\title{
SISTEM INFORMASI PERENCANAAN PEMBANGUNAN DAERAH BERBASIS WEB
}

\author{
Yuswardi (1), Husaini (2) \\ 1,2Program Studi Teknik Informatika \\ Universitas Jabal ghafur \\ 1yuswardi@unigha.ac.id,2husaini@gmail.com
}

\begin{abstract}
Mempercepat proses pelaporan data program perencanaan pembangunan daerah, untuk itu di perlukan suatu sistem informasi perencanaan pembangunan daerah pada Kabupaten Pidie berbasis web dengan mamanfaatkan Database untuk penyimpanaan datanya. Dengan adanya system dapat mempermudah serta mempercepat Kantor Badan Perencanaan dan Pembangunan Daerah Kabupaten Pidie dalam mendata dan menginformasikan data-data program pembangunan daerah di Kabupaten Pidie kepada Bupati khususnya dan kepada masyarakat luas umumnya. Sistem ini menghasilkan informasi-informasi berupa laporan data program pembangunan daerah per tahun, laporan pagu indikatif per tahun, dan laporan jumlah dokumen menurut program/kegiatan per tahun.
\end{abstract}

Key Words : Sistem, Informasi, Pembangunan, Berbasis Web

\section{Pendahuluan}

Perencanaan pembangunan daerah dirumuskan secara transparan, responsif, efisien, efektif, akuntabel, partisipatif, terukur, berkeadilan dan berkelanjutan yang meliputi Rencana Pembangunan Jangka Panjang Daerah (RPJPD) yang dilaksanakan untuk 20 tahun, Rencana Pembangunan Jangka Menengah Daerah (RPJMD) yang dilaksanakan selama 5 tahun dan Rencana Kerja Pemerintah Daerah (RKPD) untuk periode satu tahun.

Untuk menunjang mempercepat proses penginformasian program perencanaan pembangunan daerah kepada masyarakat, saat ini banyak pemerintah daerah telah memanfaatkan internet melalui media website (berbasis web) agar terciptanya transfaransi antara pemerintah dengan masyarakat.

\section{Metodelogi Penelitian}

Metode penelitian yang diterapkan dalam melakukan penelitian ini adalah

1. Studi Kepustakaan (Liberrary Research) Studi Kepustakaan yaitu sebagai bahan sekunder dan bahan studi perbandingan dalam penelitian yang penulis lakukan untuk meletakkan suatu landasan teoritis melalui buku-buku ilmiah dan bahan kuliah lain.

2. Studi Lapangan (Field Research)

Dalam hal ini penulis terjun langsung kelapangan untuk mencari informasi dan mengumpulkan data-data dengan pihak yang berhubungan dengan penelitian ini.

Tehnik pengumpulannya adalah :

a. Wawancara yaitu tehnik pengumpulan data untuk mendapatkan informasi melalui tanya jawab dengan karyawan pada Kantor Badan Perencanaan dan Pembangunan Daerah Kabupaten Pidie.

b. Pengamatan yaitu tehnik pengumpulan data dengan cara melihat langsung pada objek data yang ada hubungan dengan penulisan skripsi yang penulisan rangkumkan sebagai untuk menguatkan data.

\section{Rancangan Basis Data}

Rancangan basis data merupakan perancangan yang dilakukan untuk menentukan tabel-tabel yang digunakan 
dalam pembuatan sistem informasi perencanaan pembangunan daerah pada Kabupaten Pidie berbasis web ini.

\section{Entity Relationship Diagram (ERD)}

Entity relationship diagram (ERD) mengambarkan relasi yang terjadi antar entitas yang dilibatkan dalam basis data sistem informasi program perencanaan pembangunan daerah pada Kabupaten Pidie berbasis web. Adapun ERD untuk sistem ini dapat dilihat pada gambar berikut.

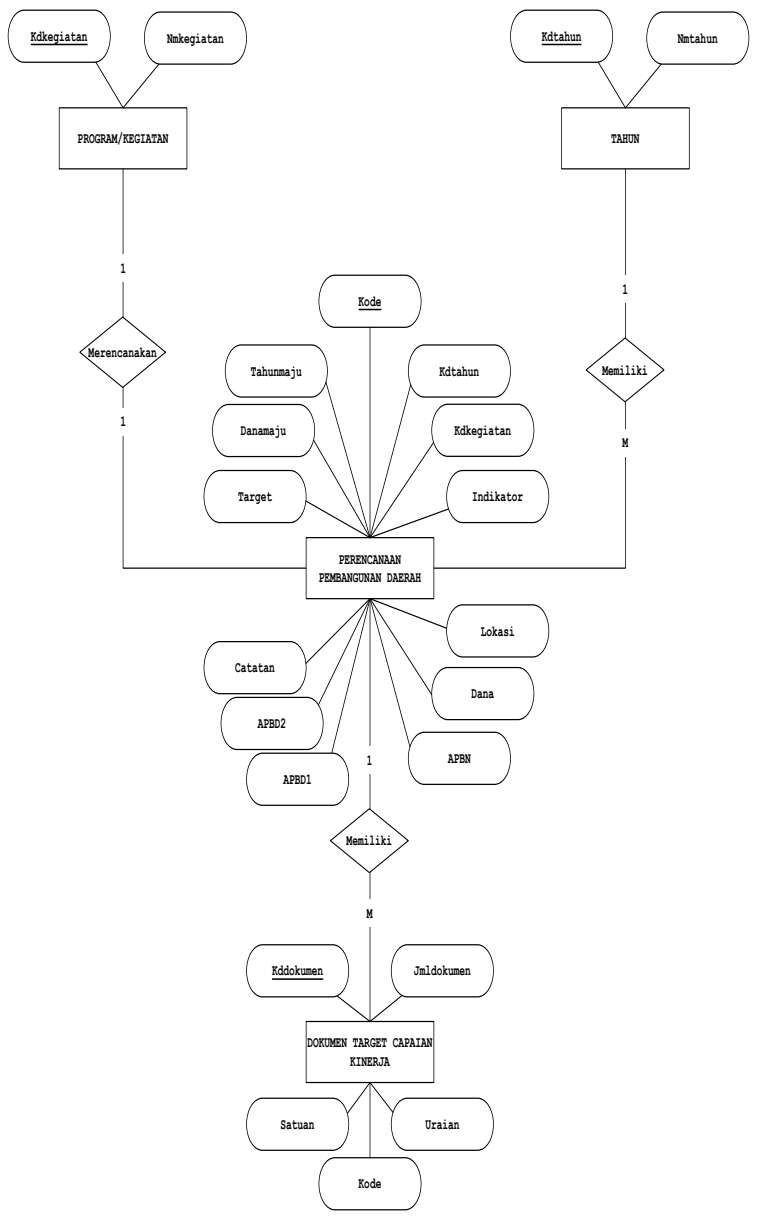

Gambar 1: Entity Relationship Diagram (ERD)

\section{Diagram Konteks}

Diagram konteks merupakan penggambaran alur data secara umum pada saat sistem dijalankan. Adapun diagram konteks untuk sistem informasi perencanaan pembangunan daerah pada Kabupaten Pidie berbasis web dapat dilihat pada gambar berikut.

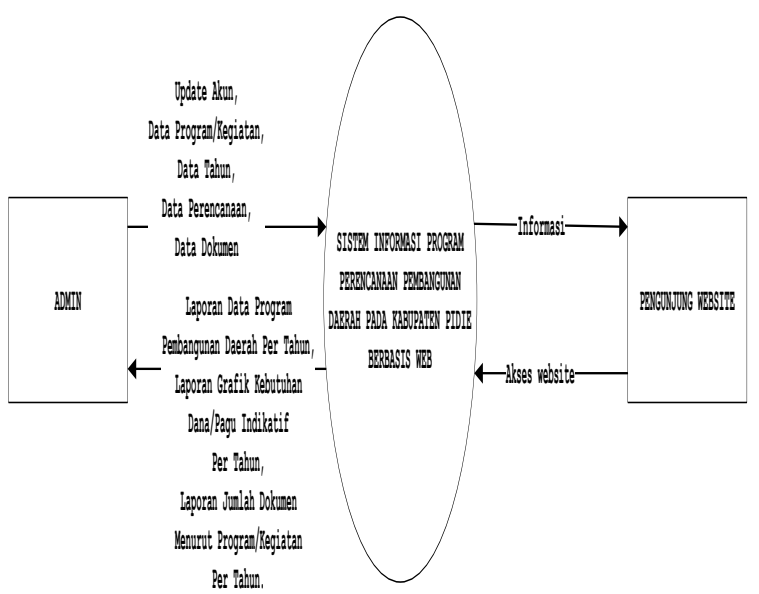

Gambar 1. Diagram Konteks

\section{Data Perencanaan}

Halaman data perencanaan ini merupakan halaman yang digunakan untuk mengelola data-data program perencanaan pembangunan daerah yang telah disusun sebelumnya. Adapun tampilan dari halaman ini dapat dilihat pada gambar berikut

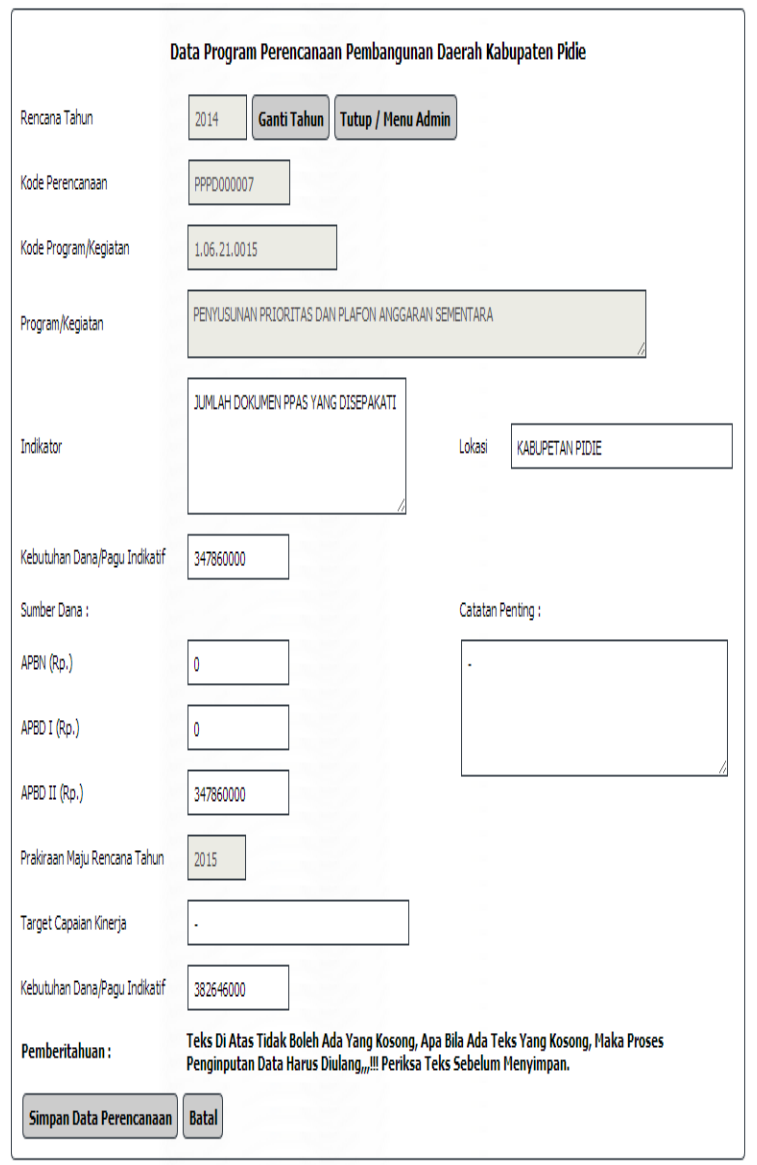

Gambar 3. Tampilan Halaman Data Perencanaan 


\section{Data Dokumen}

Halaman data dokumen ini merupakan halaman yang digunakan untuk mengelola jumlah-jumlah dokumen target capaian kinerja berdasarkan program/kegiatan dari program perencanaan pembangunan daerah. Adapun tampilan dari halaman ini dapat dilihat pada gambar berikut.

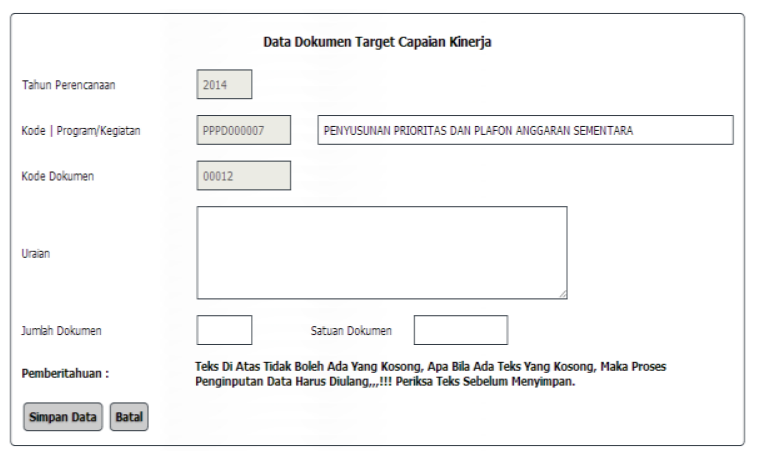

\section{Halaman Informasi}

Halaman laporan merupakan halaman yang digunakan untuk mengakses laporan-laporan yang dihasilkan oleh sistem. Adapun tampilan dari halaman ini dapat dilihat pada gambar berikut.

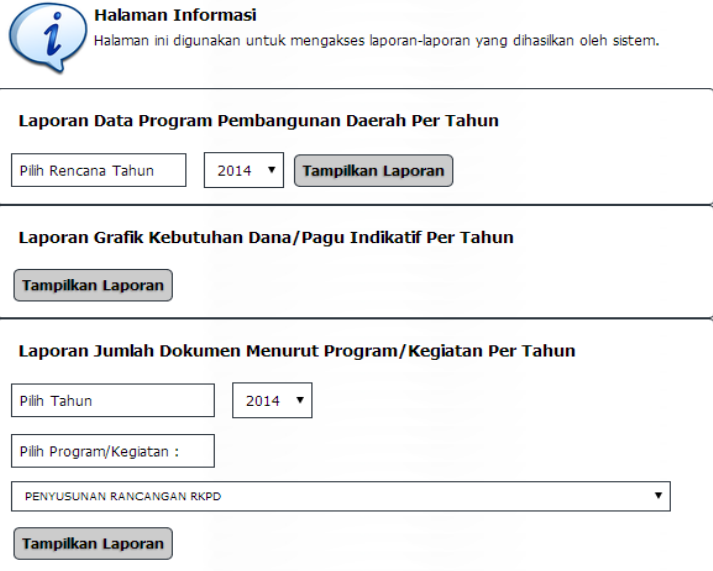

Gambar 5. Tampilan Halaman Informasi

\section{Laporan Data Program Pembangunan Daerah Per Tahun}

Laporan ini menghasilkan informasi tentang data-data program pembangunan daerah dalam Kabupaten Pidie per tahun perencanaan. Adapun tampilan laporan ini dapat dilihat pada gambar berikut.

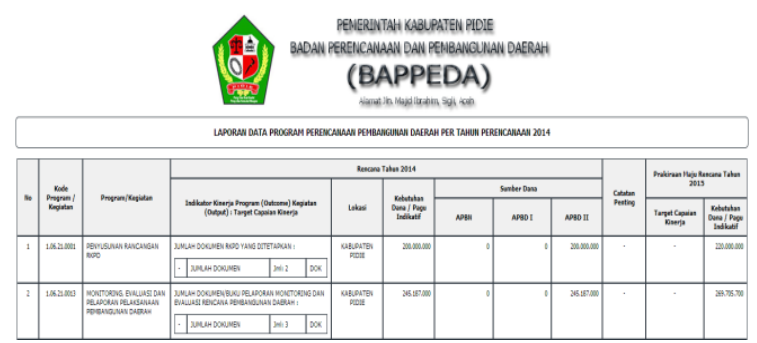

Gambar 6. Laporan Data Program Pembangunan Daerah Per Tahun

\section{Laporan Jumlah Dokumen Menurut Kegiatan Per Tahun}

Laporan ini menghasilkan informasi tentang data jumlah dokumen target capaian kinerja berdasarkan program/kegiatan yang ada dalam program perencanaan pembangunan daerah Kabupaten Pidie. Adapun tampilan laporan ini dapat dilihat pada gambar berikut.

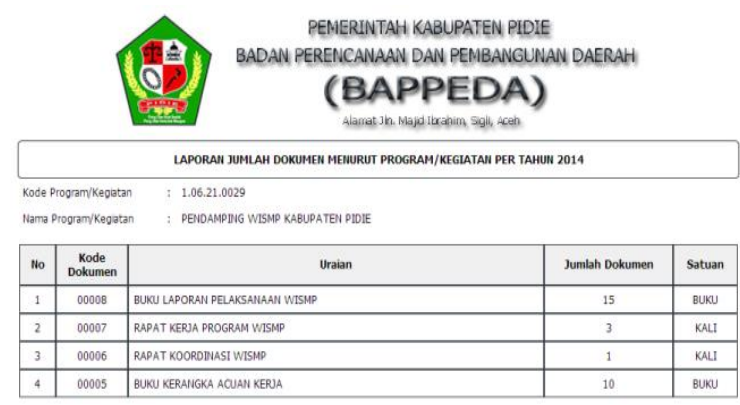

Gambar 7. Tampilan Laporan Jumlah Dokumen Menurut Program/Kegaitan Per Tahun

\section{Kesimpulan}

Dengan adanya sistem informasi perencanaan pembangunan daerah berbasis web dapat mempermudah dalam mendata perencanaan pembangunan daerah yang telah disusun sebelumnya, sehingga dapat meningkatkan pelayanan dari pemerintah daerah dalam menyajikan informasiinformasi terkait dengan data program perencanaan pembangunan daerah kepada masyarakat luas dan mempermudah bagi pencari informasi-informasi mengenai datadata program pembangunan daerah di Kabupaten Pidie, dimana dengan memanfaatkan media internet, pencari informasi dapat mengakses informasi yang 
diinginkan melalui sistem ini, hal ini telah menghemat tenaga dan waktu yang dikeluarkan oleh sipencari informasi.

\section{DAFTAR PUSTAKA}

Abdul Razaq. 2009. Membuat Bahan Ajar Berbasis Web Dengan Exe. Elex Media Komputindo: Jakarta.

Autada, IT, Solution. 2010. Pengenalan Aplikasi Macromedia Dremwever. Andi Publisher. Yogyakarta.

Bambang, Wahyudi. 2008. Konsep Sistem Informasi dari Bit Sampai Ke Database. Andi Publisher: Yogyakarta.

Cici, Selviana, Taolin. 2012. Analisis dan Perencanaan Sistem Informasi Berbasis web Pada Badan Perencanaan Pembangunan Daerah Kabupaten Belu NTT. STIMIK AMIKOM: Yogyakarta.
Jogiyanto. 2009. Sistem Teknologi Informasi: Pendekatan Terintegrasi: Konsep Dasar, Teknologi, Aplikasi, Pengembangan, dan Pengelolaan (Edisi 3). Andi: Yogyakarta.

Krisdanto, Surendro. 2009. Pengembangan Rencana Induk Sistem Informasi. Informastika: Jakarta.

Mudrajad, Kuncoro. 2004. Otonomi dan Pembangunan Daerah: Reformasi, Perencanaan, Strategi, dan Peluang. Erlangga: Bandung.

Sondang, P, Siagian. 2006. Sistem Informasi Manajemen. Bumi Aksara: Yogyakarta.

Tri, Widodo. 2006. Perencanaan Pembangunan: Aplikasi Komputer (Era Otonomi Daerah). UPP STIM YKPN: Yogyakarta. 